\title{
A Panel Data Analysis of the Brain Gain
}

M. Beine, C. Defoort and F. Docquier

Discussion Paper 2007-24

Département des Sciences Économiques

de l'Université catholique de Louvain 


\title{
A Panel Data Analysis of The Brain Gain*
}

\author{
Michel Beine $^{a}$, Cecily Defoort ${ }^{b}$ and Frédéric Docquier ${ }^{c}$ \\ ${ }^{a}$ University of Luxemburg, University of Brussels and CESifo \\ ${ }^{b}$ EQUIPPE, University of Lille and IRES, Catholic University of Louvain \\ ${ }^{c}$ FNRS and IRES, Catholic University of Louvain, IZA and CReAM
}

June 2007

\begin{abstract}
In this paper, we analyze the global impact of the mobility of talented workers on human capital accumulation. We derive testable predictions from a stylized theoretical model and test them using an original panel data set on international migration by educational attainment. We obtain conditional convergence of schooling indicators over the period 1975-2000. Our findings also reveal that skilled migration fosters human capital accumulation in lowincome countries. On the contrary, we find no evidence of a significant incentive mechanism in middle-income and, unsuprisingly, in high-income countries.
\end{abstract}

JEL Classifications: O15-O40-F22-F43

Keywords: human capital, convergence, brain drain

${ }^{*}$ This article benefited from comments received at the SIUTE seminar (Lille, January 2006), the CReAM conference on "Immigration: Impacts, Integration and Intergenerational Issues (London, March 2006), the Spring Meeting of Young Economists (Sevilla, May 2006), the XIV Villa Mondragone International Economic Seminar (Rome, July 2006) and the ESPE meeting (Chicago, 2007). Helpful suggestions from Barry Chiswick, Hubert Jayet, Joel Hellier and Fatemeh Shadman-Mehta were appreciated. The third author is grateful for the financial support from the Belgian Frenchspeaking Community's programme "Action de recherches concertées" (ARC 03/08 -302) and from the Belgian Federal Government (PAI grant P6/07 Economic Policy and Finance in the Global Equilibrium Analysis and Social Evaluation). The usual disclaimers apply. Corresponding author: Cecily Defoort, EQUIPPE, University of Lille 2, 1 Place Déliot, 59024 Lille, France. 


\section{Introduction}

An undeniably stylized fact of the last 50 years is that, with a few exceptions, the poorest countries of the world did not catch up with the industrialized nations in any meaningful way. Although a considerable amount of research has been devoted to the understanding of growth and development, economists have not yet found how to make poor countries richer. Nevertheless, in this quest for growth, increasing human capital has usually been considered as an adequate policy. In this context, it is commonly argued that the brain drain (from poor to rich countries) makes rich countries richer at the expense of the poor. By depriving poor countries of one of their scarcest resources (human capital), the brain drain is seen as exacerbating inequality across nations. The brain drain is particularly harmful if concentrated in some occupations (such as healthcare personnel, teachers, engineers, etc.) and if skilled migrants were mostly trained in their country of origin. A priori, it could be argued that lowering the brain drain would reduce inequality across nations. Our analysis reveals that a limited, but positive rate of skilled migration is likely to be beneficial for the poorest countries.

This paper belongs to the recent literature on the consequences of skilled emigration for sending countries. The cost of the brain drain in terms of lost talented workers can be compensated by large amounts of remittances ${ }^{1}$, skill diaspora effects ${ }^{2}$ and return migration ${ }^{3}$. A particular strand of the literature is even more optimistic

\footnotetext{
${ }^{1}$ Migrants' remittances often make a significant contribution to GNP and are a major source of income in many developing countries, exceeding official development assistance and foreign direct investment (see World Bank, 2006).

${ }^{2}$ Since Gould (1994), Rauch and Trindade (2002) or Rauch and Casella (2003), a large sociological literature has emphasized that the creation of migrants' diaspora facilitates the movement of goods, factors, and ideas between the migrants' host and home countries. Recent empirical studies have stressed that these diaspora externalities are mostly driven by skilled migration (see Rapoport and Kugler, 2006)

${ }^{3}$ Many theoretical works and case studies show that return migration and brain circulation are
} 
and shows that the brain drain has an ambiguous impact on human capital accumulation in developing countries. Several authors such as Stark et al. (1998), Vidal (1998), Mountford (1997), Beine et al. (2001, 2007), Stark and Wang (2002) argued that migration prospects ex-ante foster education investments in developing countries. Ex-post, some will effectively leave their country while other will stay put, thus making it possible for a brain drain to be beneficial to the source country. Basically, if the ex-ante effects is sufficiently strong, the origin country may end up with a higher level of human capital after emigration is netted out than in an autarky framework.

Is there any empirical support to this ex-ante incentive hypothesis? Their is a great deal of anecdotal evidence that migration prospects indeed impact on people's decisions to invest in higher education. For example, in their survey on medical doctors working in the UK, Kangasniemi et al. (2004) report that about $30 \%$ of Indian doctors surveyed acknowledge that the prospect of emigration affected their effort to put into studies; Commander et al. (2004) provide clear indications that the software industry's booming has been met with a powerful educational response, partly related to migration prospects. Lucas (2004) argues that the choice of major field of study (medicine, nursing, maritime training) among Filipino students respond to shifts in the international demand for skilled workers.

At the aggregate level, cross-section empirical studies by Beine et al. (2001, 2007) confirm that migration prospects have a positive and significant impact on human capital formation between 1990 and 2000. Depending on the magnitude of the

good for growth. Although the magnitude of return migration is badly known, the fact that migrants accumulate knowledge and financial capital in rich countries before spending the rest of their career in their origin country may generate beneficial effects on productivity and technology diffusion (see Dos Santos and Postel-Vinay, 2003 and 2004). A recent and comprehensive survey of India's software industry stressed the importance of temporary mobility (strong evidence of a brain exchange or a brain circulation), with $30-40 \%$ of the higher-level employees having relevant work experience in a developed country (Commander et al., 2004). 
migration rate and initial human capital stock, the ex-post response (after migration is netted out) can be positive or negative. Beine et al (2007) shows that the incentive mechanisms is also obtained when using alternative brain drain measures controlling for whether migrants acquired their skills in the home or in the host country. Finally, they also regress other indicators of human capital investment on skilled migration rates and find a positive effect on youth literacy while the effect on school enrollment depends on the exact specification used. These results are confirmed by Faini (2003) who finds a positive effect of tertiary emigration prospects on enrollment rates at the secondary level, but a non significant effect on domestic enrollment in higher education. He attributes his finding to the choice by would-be migrants to pursue their studies abroad.In a more general setting, Finally, Mariani (2005) shows that the GDP growth rate is positively affected by the skilled migration rate in countries where the middle class is sufficiently large.

The limit of these studies is that, due to data availability, they rely on crosscountry regressions. They may suffer from mispecification biases and fail at capturing the unobserved heterogeneity between countries (see Islam, 1995). In addition, the exact causality between human capital formation and skilled migration is not easy to detect, although instrumentation techniques are generally used. The main purpose of this paper is to generalize these aggregated studies using original panel data on international migration and human capital, with 6 observations by country (from 1975 to 2000). We first test for the existence and robustness of the incentive hypothesis in a $\beta$-convergence regression model of human capital accumulation. Then, we examine whether the magnitude of the incentive mechanism varies with the country level of development.

In Section 2, we describe our theoretical model characterizing human capital ac- 
cumulation in developing countries. We model the effect of skilled migration on the decision to educate and on the proportion of agents remaining in their country. We demonstrate that the effect of skilled migration on education is ambiguously linked to the country level of development. On the one hand, migration prospects have a stronger impact on the return to schooling in poor countries. On the other hand, in poor or unequal countries, liquidity constraints are likely to limit the capacity of people to respond to incentives. Our theoretical model also shows that it is important to treat the probability of migration as an endogenous variable. Section 3 presents the original panel data on skilled migration and human capital, which can be used to test the model predictions. Section 4 gives the empirical results. To account for the potential "incentive effect" of migration prospects on human capital formation in the source countries, human capital is measured as the proportion of skilled among natives, rather than among residents. Based on a cross-section $\beta$-convergence model, our results provide some support in favor of a conditional convergence process. Skilled migration prospects have a positive impact on human capital accumulation in developing countries. This incentive effect is only perceptible in low-income countries. It is not significant in lower-middle, upper-middle and, unsurprisingly, in high-income countries. Hence, the brain drain has an ambiguous impact on human capital accumulation in poor countries; however, it unambiguously decreases the average level of schooling in rich and middle-income countries. Section 5 concludes.

\section{Theory}

In this section, we describe the theoretical mechanisms underlying our empirical model and derive the main testable predictions. We consider a developing economy populated by two-period lived heterogeneous individuals. The proportion of educated 
workers is endogenous and affects the wage rate through a static externality. Hence, if skilled migration modifies the proportion of educated in the labor force (used as a proxy for the stock of human capital), it affects the welfare of those left behind.

Assume a simple production function with labor in efficiency unit as a single factor. Skilled and unskilled workers are perfect substitutes. Each unskilled worker supplies one efficiency unit of labor while skilled workers supply $\sigma>1$ such units. The production function is linear. At each period $t$, the gross domestic product $Y_{t}$ is given by

$$
Y_{t}=w_{t} L_{t}
$$

where $L_{t}$ is the total labor force in efficiency unit, and the wage rate per efficiency unit of labor, $w_{t}=w\left(\pi_{t}, X_{t}\right)$, is an increasing function of the proportion of skilled adults, $\pi_{t}$, and of country-specific characteristics $X_{t}$ (such as public infrastructure, governance, etc.). We have $w^{\prime}=\frac{\partial w}{\partial \pi}>0$ but impose no restriction on the sign of second derivative $w^{\prime \prime}=\frac{\partial w^{2}}{\partial^{2} \pi} \lessgtr 0$, thus allowing for threshold externalities à la Azariadis and Drazen (1990). Consequently, the social return to education $\left(\sigma+w^{\prime}\right)$ exceed the private return $(\sigma)$.

Young individuals offer one unit of human capital and earn the minimal wage $w_{t}$. They have the possibility to spend a part of their income into education. There is a single education program and individuals are heterogeneous in their ability to learn. Agents are characterized by different education costs, with high-ability individuals incurring a lower cost. The cost of education is expressed as a proportion of the wage rate of teachers (considered as skilled workers). For a type- $c$ agent, the cost is denoted by $\alpha_{t} c \sigma w_{t}$ where $\alpha_{t}$ is the non-subsidized proportion of education expenditure ${ }^{4}$. For

\footnotetext{
${ }^{4}$ This variable is introduced to show how local policies affect human capital formation. Since we focus on a partial equilibrium model, we disregard taxation issues, i.e. how education policies are financed.
} 
simplicity, the variable $c$ is distributed on $[0,1]$ according to a uniform density. We have $c=0$ for the highest ability and $c=1$ for the lowest ability agent.

In adulthood, individuals offer all their time on the labor market with heterogeneous abilities to produce. Unskilled adults receive $w_{t}$ whilst skilled workers receive $\sigma w_{t}$

There is no saving so that the utility depends on the first and expected secondperiod incomes. For simplicity, utility is log-linear and there is no time-discount rate. We have

$$
u_{t}=\ln \left(y_{1, t}-\mu\right)+\ln \left(y_{2, t+1}\right)
$$

where $\mu$ is the level of subsistence when young. Such a parameter is important to model the absence of convergence between poor and rich countries. It is assumed that $w_{t}=w\left(0, X_{t}\right)>\mu$. We assume no subsistence level in the second period of life for mathematical convenience.

With this stylized model, we first characterize the closed economy equilibrium and then examine the effect of skilled emigration on welfare and economic activity.

Closed economy benchmark (subscript $\mathbf{n}$ ). Individuals choose their education so as to maximize their lifetime utility. The lifetime income for an uneducated agent is

$$
u_{n, t}=\ln \left(w_{t}-\mu\right)+\ln \left(w_{t+1}\right)
$$

By contrast, the lifetime income for a type- $c$ educated agent is

$$
u_{n, t}=\ln \left(w_{t}-c \alpha_{t} w_{t} \sigma-\mu\right)+\ln \left(w_{t+1} \sigma\right) .
$$

Clearly, education is optimal for individuals whose education cost is low. The condition for investing in education in an economy with no migration is: 


$$
c<c_{n, t} \equiv \frac{w_{t}-\mu}{\alpha_{t} w_{t}} \times \frac{\sigma-1}{\sigma^{2}}
$$

where the cut-off ability level $c_{n, t}$ is an increasing function of the local wage rate $w_{t}$ but a decreasing function of the share of education supported by individual $\alpha_{t}$ (one minus the subsidy rate). In a closed economy and given our specifications, the proportion of educated is independent of the expected wage rate $w_{t+1}$. Note that $c_{n, t}$ increases in $\sigma$ when $\sigma$ is lower than 2. Let us assume $\sigma \in[1,2]$ in what follows. Given the particular utility function, the exogeneity of the skill premium and the way we introduce education costs, this hypothesis is necessary to ensure the existence of an interior solution with a proportion of educated between 0 and 1 .

The proportion of educated adults is given by the lagged proportion of young individuals opting for education, $\pi_{t+1}=c_{n, t}$. As $w_{t}$ is a function of $\pi_{t}$, our closed economy model is compatible with the existence of poverty traps. Polarization in incomes suggests that the world growth process departs from the predictions of the one-sector, convex model with complete markets (see Azariadis and Stachurski, 2005). The future proportion of educated depends on the current proportion through the wage externality. We have

$$
\begin{aligned}
\frac{d \pi_{t+1}}{d \pi_{t}} & =\frac{\sigma-1}{\alpha_{t} \sigma^{2}} \cdot \frac{\mu}{w_{t}^{2}} \cdot w^{\prime}>0 \\
\frac{d \pi_{t+1}^{2}}{d^{2} \pi_{t}} & =\frac{\sigma-1}{\alpha_{t} \sigma^{2}} \cdot \frac{\mu}{w_{t}^{2}} \cdot\left[w^{\prime \prime}-2 \cdot w^{\prime} \cdot w_{t}\right] \lessgtr 0
\end{aligned}
$$

Although this is not an essential feature of our model, the existence of a subsistence level $(\mu)$ and wage externalities $\left(w^{\prime}>0\right)$ can give rise to multiple steady states. With exogenous wages or no subsistence level, the critical ability $c_{n, t}$ would be independent of historical records. 
Introduction of probabilistic skilled migration (subscript q). In poor countries, the enrollment in education is low for two possible reasons. Firstly, only a few people can afford paying the education costs; secondly, domestic returns to education can be too small. Our closed economy model perfectly matches these two ingredients. Let us now consider that a fraction $p_{t}$ of skilled workers can leave the country at time t. For simplicity, we assume that unskilled workers have no access to migration. This hypothesis is reasonable given the recent evolution of immigration policies in rich countries. The data reveal huge differentials in migration rates between skilled and unskilled workers.

If $c_{q, t-1}$ denotes the proportion of young agents opting for education in a probabilistic migration framework, the proportion of skilled in the remaining adult population becomes:

$$
\pi_{t}=\frac{\left(1-p_{t}\right) \cdot c_{q, t-1}}{1-p_{t} \cdot c_{q, t-1}}
$$

Ex-post (i.e. for a given proportion of educated, $c_{q, t-1}$ ), it is obvious that the skilled emigration rate reduces $\pi_{t}$. However, education is more and more considered as a route to emigration. As candidates leave nothing to chance, migration prospects may affect the expected return to education and induce them to educate more. Then, given quota systems and various types of requirements and restrictions imposed by immigration authorities (such as the point systems), there is a probability that the migration project will have to be postponed or abandoned at all stages of the immigration process. Individuals engaging in education investments with the prospect of migration must therefore factor in this uncertainty. Ex-ante, the expectation of $p_{t}$ can increase the proportion of young agents engaging in education, $c_{q, t-1}$, creating the possibility of a net gain for the source country. 
To formalize this idea, let us now denote by $w^{*}$ the net-of-migration-cost wage rate in industrialized host countries. In high-income or upper-middle-income countries where the domestic wage rate is equal or higher than $w^{*}$, migration prospects does not affect education choices. In low-income and lower-middle-income countries, skilled migration increase the expected return to education. For simplicity, we assume a constant skill premium across countries and periods and consider that the sending country is too small to affect the wage rate in the North.

Young agents now educate by anticipating a probability $p_{t+1}$ of emigrating to the rich country. The expected lifetime utility for an uneducated agent is

$$
u_{q, t}=\ln \left(w_{t}-\mu\right)+\ln \left(w_{t+1}\right)
$$

The expected lifetime utility for an educated agent now becomes

$$
u_{q, t}=\ln \left(w_{t}-c \alpha_{t} w_{t} \sigma-\mu\right)+p_{t+1} \ln \left(w^{*} \sigma\right)+\left(1-p_{t+1}\right) \ln \left(w_{t+1} \sigma\right)
$$

Clearly, education is worthwhile for individuals whose education cost is lower than a critical value. The condition for investing in education in an economy with migration (henceforth denoted using the subscript $q$ ) is:

$$
c<c_{q, t} \equiv \frac{w_{t}-\mu}{\alpha_{t} w_{t}} \cdot \frac{\sigma\left(\frac{w^{*}}{w_{t+1}}\right)^{p_{t+1}}-1}{\sigma^{2}\left(\frac{w^{*}}{w_{t+1}}\right)^{p_{t+1}}}
$$

Clearly, if $p_{t+1}=0$ or if $w_{t+1}=w^{*}$, we obtain the same proportion as in the closed economy $\left(c_{q, t}=c_{n, t}\right)$. Otherwise, when $\left(\frac{w^{*}}{w_{t+1}}\right)^{p_{t+1}}>1$, the critical level of ability increases and more individuals engage in education. Formally, the proportion of young engaging in education $c_{q, t}$ is characterized by the following derivatives:

$$
\frac{\partial c_{q, t}}{\partial w_{t}}=\frac{\sigma\left(\frac{w^{*}}{w_{t+1}}\right)^{p_{t+1}}-1}{\sigma^{2}\left(\frac{w^{*}}{w_{t+1}}\right)^{p_{t+1}}} \cdot \frac{\mu}{\alpha_{t} w_{t}^{2}}>0
$$




$$
\begin{aligned}
\frac{\partial c_{q, t}}{\partial w_{t+1}} & =-\frac{w_{t}-\mu}{\sigma^{2} \alpha_{t} w_{t}} \cdot p_{t+1}\left(\frac{w^{*}}{w_{t+1}}\right)^{-p_{t+1}-1} \frac{w^{*}}{w_{t+1}^{2}}<0 \\
\frac{\partial c_{q, t}}{\partial p_{t+1}} & =\frac{w_{t}-\mu}{\sigma^{2} \alpha_{t} w_{t}} \cdot\left(\frac{w^{*}}{w_{t+1}}\right)^{-p_{t+1}} \ln \left[\frac{w^{*}}{w_{t+1}}\right]>0 \text { if } w^{*}>w_{t+1}
\end{aligned}
$$

On the contrary, when $w^{*}<w_{t}$ (rich origin country), migration prospects do not affect education choice and we have $\frac{\partial c_{q, t}}{\partial p_{t+1}}=0$ and $c_{q, t}=c_{n, t}$. The following testable propositions emerge:

Proposition 1 In developing countries where $w_{t+1}<w^{*}$, the ex-ante investment in education is an increasing function of the skilled emigration rate. The size of the response ambiguously depends on the country level of development. On the one hand, the poorer the origin country ( $w_{t}$ is low), the lower is the capacity of agents to respond to migration prospects. On the other hand, the poorer the origin country $\left(w^{*} / w_{t+1}\right.$ is high), the higher is the incentive impact of migration on the expected return to education. In rich countries where $w_{t+1} \geq w^{*}$, skilled migration rates should not impact on education choices.

Such a proposition can be empirically tested by regressing natives' human capital formation on variables interacting with emigration rates and country level of development. As $\alpha_{t}$ and $X_{t}$ also affect the results in our stylized model, adding other country-specific variables or fixed effects also makes sense.

The need to endogenize emigration rates. Although skilled individuals form expectations on the future probability to emigrate, this probability must be considered as potentially endogenous. Due to immigration restrictions, suppose that the receiving country is willing to accept a number $Q_{t}$ of educated immigrants at time $t$. The immigration quota $Q_{t}$ represents a maximal fraction $q_{t}$ of the adult population at time $t$. Hence, the higher the proportion of educated adults, the lower the probability that 
each of them will leave the country. Under perfect foresights, individuals anticipate $p_{t+1}=q_{t+1} / c_{q, t}$ which is clearly a negative function of the proportion of educated ${ }^{5}$. Although explicit origin-based-quota systems are seldom observed in OECD countries, this prediction is compatible with the stylized facts and empirical findings presented in Docquier, Lohest and Marfouk (2007): ceteris paribus, an increase in natives' average level of schooling reduces the skilled emigration rate.

Endogenizing the probability of emigration in (8), the equilibrium proportion of educated among natives is now determined by the following implicit equation

$$
c_{q, t} \equiv \frac{w_{t}-\mu}{\alpha_{t} w_{t}} \cdot \frac{\sigma\left(\frac{w^{*}}{w_{t+1}}\right)^{q_{t+1} / c_{q, t}}-1}{\sigma^{2}\left(\frac{w^{*}}{w_{t+1}}\right)^{q_{t+1} / c_{q, t}}}
$$

which determines the ex-ante proportion of educated: $c_{q, t}=c_{q}\left(w_{t}, \alpha_{t}, w^{*}, w_{t+1}, q_{t+1}\right)$. The expression for $\frac{d c_{q, t}}{d q_{t+1}}$ can be obtained by applying the implicit function theorem.

The proportion of educated among remaining adults is now given by

$$
\pi_{t+1}=\frac{c_{q, t}\left(1-p_{t+1}\right)}{1-p_{t+1} c_{q, t}}=\frac{c_{q, t}-q_{t+1}}{1-q_{t+1}}
$$

Since $c_{q, t}$ depends on $w_{t+1}$, itself influenced by $\pi_{t+1}$, the above equation for $\pi_{t+1}$ is also an implicit function. The endogeneity of the probability of migration has theoretical and empirical implications. Theoretically, it affects the global impact of skilled migration on the remaining proportion of educated $\pi_{t+1}$. Using the implicit function theorem, we obtain

$$
\frac{d \pi_{t+1}}{d q_{t+1}}=\frac{\frac{d c_{q, t}}{d q_{t+1}}-\left(1-\pi_{t+1}\right)}{1-q_{t+1}-\frac{d c_{q, t}}{d w_{t+1}} \cdot \frac{d w_{t+1}}{d \pi_{t+1}}}
$$

The general expression is quite long and complex. As $\frac{d c_{q, t}}{d q_{t+1}}$ and $\left(1-q_{t+1}\right)$ decreases in $q_{t+1}$, the relationship between $\pi_{t+1}$ and $q_{t+1}$ is concave. When $q_{t+1}$ is equal

\footnotetext{
${ }^{5}$ Note that in the case of myopic expectations (i.e. $p_{t+1}=p_{t}=q_{t} / c_{p, t-1}$ ), we would have the same long-run equilibrium. The only difference is that the transition path is different than under perfect expectations.
} 
to zero, the closed economy solution $c_{n, t}$ applies. If $c_{q, t}=q_{t+1}$, the proportion of educated falls to its minimum $\left(\pi_{t+1}=0\right)$. Between these two extreme values, migration prospects increase or decrease $\pi_{t+1}$ depending on the size of the incentive effect. A beneficial effect on human capital can be obtained when the above derivative evaluated at $q_{t+1}=0$ is positive. In that case, there exists a range of $q_{t+1}$ increasing the proportion of remaining educated adults compared to the closed economy solution. After straightforward manipulations, this condition requires the wage differential to bo sufficiently strong:

$$
\frac{1}{\sigma-1} \ln \left(\frac{w^{*}}{w_{0}}\right)>1-\frac{w_{0}-\mu}{\alpha w_{0}} \cdot \frac{\sigma-1}{\sigma^{2}}
$$

where $w_{0}$ is the equilibrium wage rate in the closed economy.

Empirically, it implies that it is crucial to use instrumentation technique to estimate the effect of skilled migration on the formation of human capital in origin countries.

\section{Human capital and migration data}

The model prediction can be tested by regressing the ex-ante human capital investment of natives (i.e. residents + emigrants) on skilled emigration rates and countryspecific effects. Our dependent variable will be the log-change in the proportion of tertiary educated (individuals with post-secondary education or with more than 13 years of schooling) among natives. This requires collecting data on human capital of residents and emigrants.

Several data sets provide the residents' proportion of tertiary educated people in each country. Our data are mostly based on the well-known data set built by Barro and Lee (2001) for developing countries, and on De La Fuente and Domenech (2002) 
for OECD countries. For countries where Barro and Lee measures are missing, we use Cohen and Soto (2001) indicators or transpose the proportion observed in the neighboring country with the closest domestic enrollment in tertiary education. This method is used in Docquier and Marfouk (2006) for computing residents' human capital stocks in 1990 and 2000. We generalize this method and build similar data on a period ranging from 1975 to 2000 with periods of five years.

Regarding the education structure of emigrants, we rely on a new panel data set presented in Defoort (2006). The methodology follows the World Bank-sponsored study by Docquier and Marfouk (2006) which provides emigration rates by education attainment for all countries in 1990 and 2000. The skill levels considered are fully consistent with the ones used for capturing the human capital level. This data set relies on two steps. First, emigration stocks by education level are computed by aggregating census and register data collected in all OECD countries ${ }^{6}$. Second, these stocks are expressed as percent of the native labor force born in the sending country (including migrants themselves) with the same education attainment. Basically, Docquier and Marfouk (2006) provide estimates of the brain drain phenomenon for 175 countries in 1990 and 195 countries in 2000. These estimates were used in cross-country regressions supporting the incentive mechanism in Beine et al. (2007).

Defoort (2006) uses a similar methodology but, in order to overcome the limitations of cross-section approaches, she extends the time series dimension to cover the period 1975-2000 with data sampled at a five-year frequency. Unfortunately, census and register data cannot be obtained from all OECD countries on such a long horizon. Consequently, she has to focus on a more limited number of host countries. She

\footnotetext{
${ }^{6}$ In each OECD country, the census or national register gives the number of immigrants by country of birth and education level.
} 
collects census data on immigration by country of birth and by education attainment from the 6 major receiving OECD countries, i.e. Canada, Australia, the US, the UK, France and Germany ${ }^{7}$. Compared to Docquier and Marfouk (2006), these 6 countries represent 77 percent of the OECD skilled immigration stock in 2000. However, for particular countries sending a small proportion of their migrants to the 6 major destinations, the estimates can be much less reliable ${ }^{8}$ For each origin country, we construct a reliability rate equal to the 2000 share of the 6 host nations in the skilled emigration stock in the OECD. In our regressions, we either exclude observations characterized by a reliability rate lower than 70 percent or use reliability rates in weighted least squares models.

The data set reveals interesting features. Although globalization and selective immigration policies have undoubtedly increased the number of skilled emigrants to the OECD, the intensity of the brain drain has been extremely stable at the world level or at the level of developing countries as a whole. This can be explained by two important supply changes at origin: (i) the population size in developing countries has increased hugely and (ii) all countries (even the poorest ones) experienced a remarkable rise in education attainment. As shown on Figure 1, some regions experienced an increase in the intensity of the brain drain (Central America, Eastern Europe, South Central Asia and Sub Saharan Africa) while significant decreases were observed in other regions (notably the Middle East and Northern Africa). Regions where the brain drain increased significantly are those where education progresses were small and conversely. This reinforces the need to endogenize the probability of

\footnotetext{
${ }^{7}$ In some cases, reasonable interpolations are required to evaluate the structure of immigration between two national censuses. See Defoort (2006) for more details.

${ }^{8}$ For example, this is typically the case of Surinam sending most of their migrants to the Netherlands.
} 
migration in regressions.

Figure 1. Long-run trends in skilled emigration

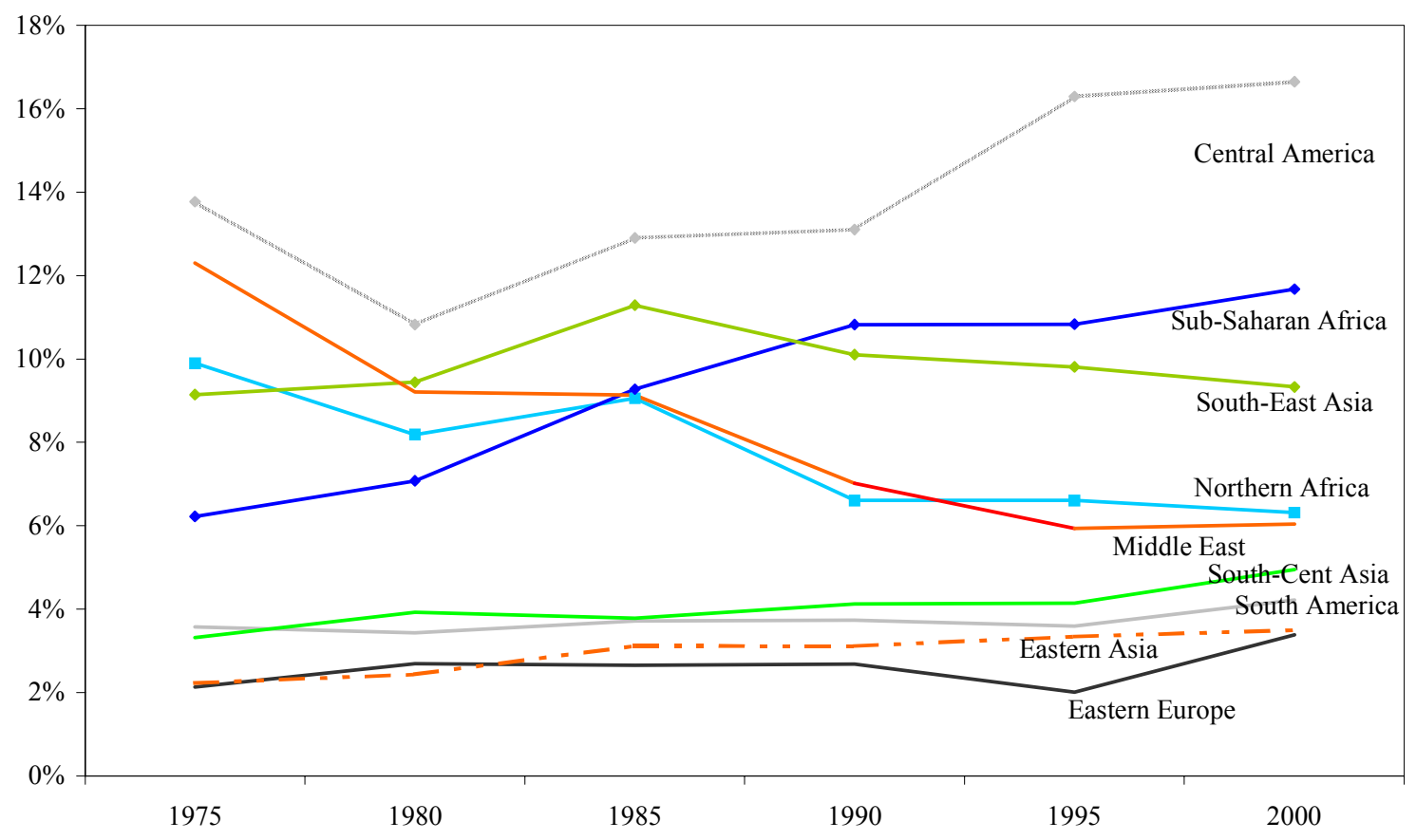

\section{Panel data analysis}

Our empirical investigation relies on the standard framework of convergence models.

In particular, we will analyze the dynamics of human capital accumulation in all countries and evaluate the role of migration of skilled workers. To account for the potential incentive effect of migration prospects on human capital formation, we measure human capital as the proportion of high-skill natives, rather than high-skill residents. We disregard the country where education was acquired. This assumption is primarly guided by the data: international migrants are defined on the basis of their country of birth, wherever they were trained. This contrasts with Rosenzweig 
(2007) who emphasizes the effect of migration prospects on student migration. The outsourcing of education is followed by subsequent returns, which are potentially beneficial for poor countries.

Our model combines the time series dimension and the cross section variation of the data. Beyond the mere advantage of using much more observations, there are a set of reasons that justify the use of a panel data approach rather than a pure cross-section analysis. First, as well documented by Islam (1995) for income levels, cross section results are subject to important mispecification biases. Failure to control for the factors that influence the human capital accumulation process leads to omitted-variable biases as these factors are likely to be correlated with the initial level of human capital. While the migration rates of skilled workers might be one of these factors, a number of unobservable factors are likely to influence human capital accumulation. ${ }^{9}$ Assuming that these factors are constant over time, a panel data analysis can take that into account through the introduction of country specific effects capturing part of the unobserved heterogeneity. The fact that the introduction of fixed effects accounts only for the time-invariant unobservable factors is much less limitative that it seems at first glance. First, a lot of factors such as ethnic diversity or degree of urbanization are relatively stable over time. Second, other factors such as the cost of education or the quality of institutions exhibit a lot of inertia over time. It is thus unclear whether their explicit inclusion (should we have observations for these factors) in the regression model would improve significantly the quality of fit and would reduce the degree of misspecification bias.

Second, extending the analysis to a panel dimension allows to account for the

\footnotetext{
${ }^{9}$ For instance, it is not possible to introduce education expenditures in the panel data analysis due to the high number of missing information in most countries for a lot of years.
} 
effect of shocks to human capital accumulation common to all countries. This is indeed important for human capital levels since education levels have obviously improved around the world along with increased globalization. Third, as for the role of migration, a pure cross section analysis would implicitly assume a constant rate of emigration of skilled workers for each country. This is obviously a strong assumption.

The regression model. Our regression model is based on a convergence equation with migration rates of skilled workers influencing the long-run levels of human capital among natives. We regress the average annual growth rate of natives' human capital on the skilled migration rate and on the initial level of human capital, first allowing heterogenous responses for developing and rich countries:

$$
\frac{1}{5} \ln \left(\frac{h_{i, t}}{h_{i, t-1}}\right)=\alpha+\alpha_{i}+\delta_{t}+\gamma_{r} m_{i, t}^{r}+\gamma_{d} m_{i, t}^{d}+\beta \ln \left(h_{i, t-1}\right)+\epsilon_{i, t}
$$

where $h_{i, t}$ denotes the level of human capital of natives for country $i$ at time $t$ (similar notations hold for the migration rates), $\alpha_{i}$ is the country-specific fixed effect capturing the influence on the long-run level of human capital of country-specific factors that are constant over time, $\delta_{t}$ captures the impact of common shocks across countries specific to year $t^{10}, m_{i, t}^{r}$ and $m_{i, t}^{d}$ are the migration rate of skilled workers coming from respectively rich and developing countries (following the World Bank classification), $\beta$ is a parameter measuring the speed of convergence to the long-run level of human capital.

As a benchmark, this equation is estimated using fixed (time and individual) effects on our samples. ${ }^{11}$ For the sake of robustness, we also consider alternative

\footnotetext{
${ }^{10}$ It should be emphasized that the estimates of $\delta_{t}$ are all highly significant at the $1 \%$ level. They suggest that the growth rate of human capital was on average increasing over time.

${ }^{11}$ Hausman tests (not reported here to save space) strongly reject the inclusion of random effects. Furthermore, from a conceptual point of view, the use of random effects does not make much sense since we include almost all the countries of the world.
} 
techniques that account for specific methodological issues at stake here.

First, equation (11) is dynamic in the sense that $\ln \left(h_{i, t-1}\right)$ enters as an explanatory variable. The use of fixed effects and AR terms leads to inconsistency of estimates, especially when the number of periods is increasing (Nickell, 1981). Although the ratio of the cross-section dimension to the time dimension suggests that the Nickell bias should be limited in our regressions, it is interesting to look at alternative approaches. This is especially important here given the seemingly high rate of convergence we get with the fixed effects specification. One way to overcome this problem is to use instrumental variable estimation. To this aim, we estimate the model using GMM regressions ${ }^{12}$ to assess the robustness of the results.

Under the null that $\beta=0$ (unit root hypothesis), the t-ratio statistic will be asymptotically normally distributed for fixed $T$ and $N \rightarrow \infty$. For finite $N$, the distribution might not be non standard and formal unit root tests might be required. Since our focus is not on a specific test of the unit root hypothesis and the interest lies in the effect of migration rates on the long-run values of human capital, we estimate equation (11) using standard techniques such as FGLS or GMM. Furthermore, the size of the t-ratios obtained for $\beta$ suggests that the case for a unit root is quite low.

As abundantly discussed in the theoretical framework, a second problem concerns the endogeneity of migrations rates of skilled workers $\left(m_{i, t}^{r}\right.$ and $\left.m_{i, t}^{d}\right)$ with respect to the change in the human capital level. Basically, one can expect that migration rates will be lower in countries in which the increase in the level of education has been relatively stronger. Failure to account for some potential reverse causality is likely to result in biased estimates of the parameters in general, and of $\gamma_{r}$ and $\gamma_{d}$ in particular. To account for that, we use instrumental variable estimation to estimate

\footnotetext{
${ }^{12}$ See Arrelano and Bond (1991), Arellano and Bover (1995), or Blundel and Bond (1992).
} 
equation (11). More precisely, we use lagged values of $m_{i, t}^{r}$ and $m_{i, t}^{d}$ as instruments of the migration rates. First stage regressions show that $m_{i, t-1}^{r}$ and $m_{i, t-1}^{d}$ are strong predictors of current migration rates with $t$-statistics above 9 and 10 respectively.

Finally, we also address the issue of the reliability of the sample. As discussed above, our panel data set is based on migration data collected in 6 major receiving countries. Our data capture a fraction of the skilled emigration to the OECD. Basically, the lower the proportion of migrants to OECD countries, the lower is the degree of reliability of the migration data. In a first step, we eliminate countries sending less than $70 \%$ of their skilled migrants to the 6 main destinations, which leads to a significant loss of information. In a second step, we also use weighted FE estimation in which the regression weights are given by the 2000 proportion of skilled migrants captured in our sample. This allows to include more than 20 additional countries in the regression sample.

Table 1 provides the estimation results of equation (11) using the four different approaches explained above. Column (1) reports the estimates with the fixed effect estimation. Column (2) gives the results using the GMM estimation procedure. Columns (3) and (4) provide the instrumental variable estimation results, for the full model and the parsimonious one. Column (5) gives the parameter estimates with the weighted fixed effect estimation procedure. Finally, Column (6) gives estimates for the random-effects (RE) model. 
Table 1: Human capital and migration prospects: panel data results

$\begin{array}{ccccccc}\text { Variables } & (1) & (2) & (3) & (4) & (5) & (6) \\ \text { Constant } & -.138^{* * *} & -.082^{* * *} & -.123^{* * *} & -062^{* * *} & -.136^{* * *} & -.003 \\ & (0.016) & (0.012) & (0.018) & (0.015) & (0.017) & (0.008) \\ \beta & -.111^{* * *} & -.074^{* * *} & -.117^{* * *} & -.118^{* * *} & -.110^{* * *} & -.013^{* * *} \\ & (0.009) & (0.007) & (0.007) & (0.007) & (0.009) & (0.001) \\ \gamma_{r} & 0.071 & 0.079 & 0.172 & - & 0.070 & 0.018 \\ & (0.073) & (0.068) & (0.276) & - & (0.056) & (0.019) \\ \gamma_{d} & 0.060^{* *} & 0.108^{* *} & 0.148^{* *} & 0.147^{*} & 0.058^{* *} & 0.015^{*} \\ & (0.027) & (0.044) & (0.068) & (0.068) & (0.027) & (0.009) \\ \text { Nb. obs. } & 735 & 735 & 588 & 588 & 855 & 735 \\ \text { Nb. countries } & 147 & 147 & 147 & 147 & 171 & 147 \\ \mathrm{R}^{2} & 0.6145 & - & 0.5552 & 0.5561 & 0.6064 & 0.0943\end{array}$

Note: Estimated equation (11). Fixed effects $\alpha_{i}$ and $\delta_{t}$ not reported. P-value: ${ }^{*} \mathrm{p}<0.1$, ${ }^{* *} \mathrm{p}<0.05,{ }^{* * *} \mathrm{p}<0.01$. In column (1), fixed-effects (FE) estimates are included. In column (2), the GMM procedure is used to account for the endogeneity of the lagged dependent variable. Columns (3) reports the instrumental variable estimation with emigration rates instrumented by their lagged values. Column (4) gives the parsimonious version of column (3). Column (5) gives the FE estimates with regression weighted by the proportion of OECD migrants captured in the data set. Column (6) gives estimates for the randomeffects (RE) model. Note that the Hausman test stongly rejects the RE specification. The Hansen/Sargan J test (not reported here) supports the validity of the instruments in GMM regressions. Note that since we have no overidentification degree in IV regressions, the Hansen/Sargan J test is not conducted for IV estimates. Nevertheless, the Anderson test supports the relevance of lagged migration rates as instruments in IV regressions.

Results of Table 1 suggest that our findings are robust to the use of alternative methods and approaches. These findings can be summarized as follows. First, our results suggest that a catching-up process in terms of education level has taken place over the investigation period. The coefficient relative to the initial value of human capital is always highly significant. Furthermore, the implied speed of convergence (towards the country-specific steady state) is quite homogeneous across regressions. It ranges from $15 \%$ to $20 \%$ per year.

Second, the results suggest that the emigration of skilled workers from developing to rich countries tends to exert a positive impact on the long-run level of human 
capital of these countries. The coefficient of $m_{i, t}^{d}$ is always significantly positive in all regressions. This means that the obtained incentive effect is robust to the use of alternative regression methods. The IV method is nevertheless the only one coping explicitely with the possible endogeneity of migration rates. Therefore, we will use the IV method in subsequent regressions allowing for various schemes of country classification.

Although Table 1 suggests that the results are qualitatively similar caross regression techniques, the value of the estimated coefficient of $m_{i, t}^{d}$ does vary quite significantly. The size of the incentive effect is found to be quite higher with IV estimates compared to fixed effect of GMM estimates. This suggests that accounting for the endogeneity of migration rates is important for the assesment of the incentive effect in poor countries. The differences between the estimated coefficients of $m_{i, t}^{d}$ raises the question of the forecastibility of the models. To address this issue, we proceed for all estimated models to in-sample simulations of the human capital level. Using estimates of Table 1 and on the basis of the initial value of the human capital level (observed in 1975), we start from the observations for $h_{i, 1975}$ (human capital levels in 1975 ) anduse (11) to forecast the values in 2000. Figure 2 plots the observed human capital distribution in 2000 with the simulated one for the four alternative regression techniques (FE, GMM, IV and RE). The first three regression techniques that rely on fixed effects lead to extremely similar forecasts which are relatively close to the observations. This contrasts with the RE effects model that leads to poor forecast of the HK distribution. This is consistent with the results of the Hausman test which tends to favour the use of fixed rather than random effects. 
Figure 2: In-sample simulation of the human capital distribution in 2000

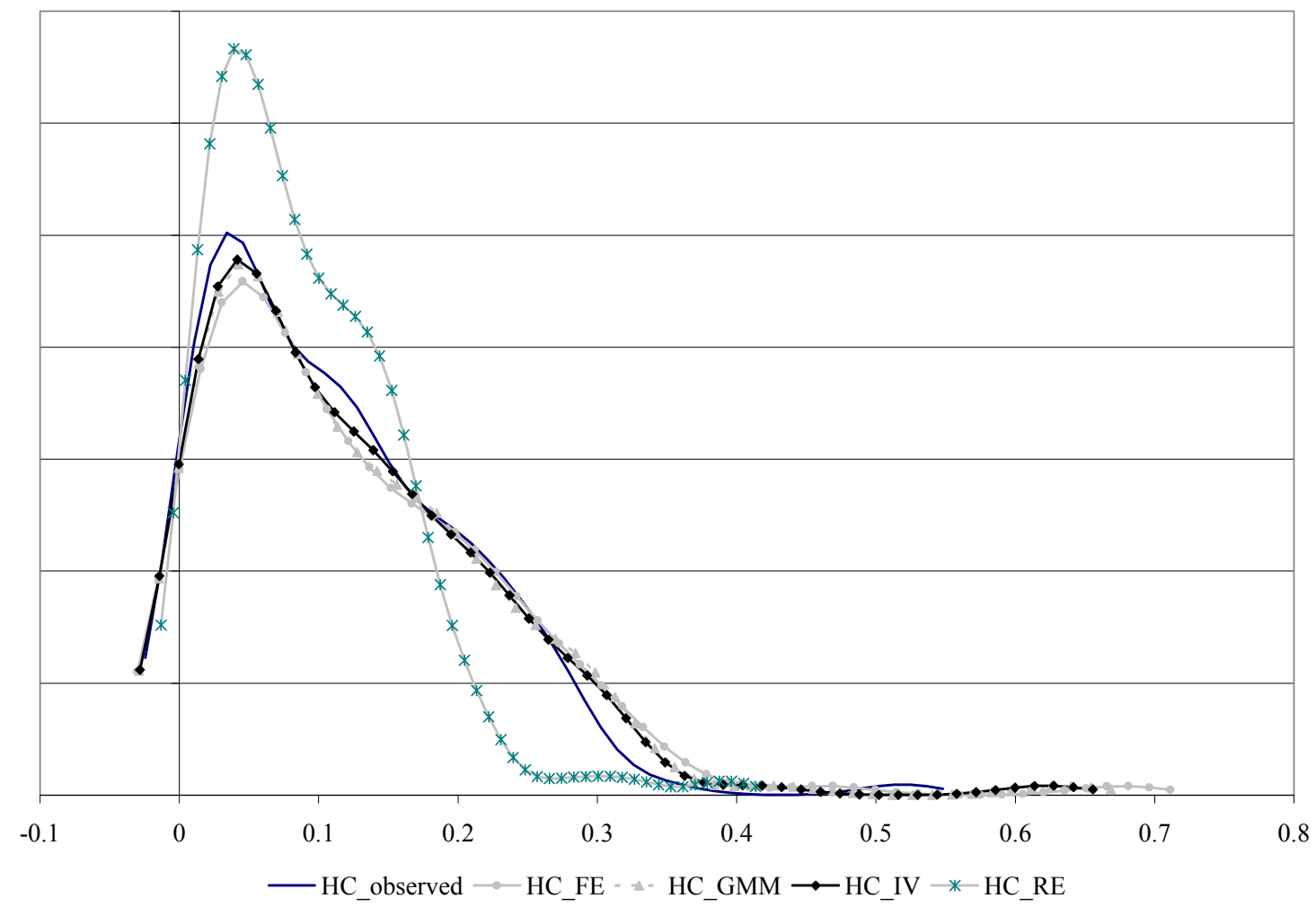

HC_observed $=$ observed distribution of human capital in 2000; .HC_FE $=$ simulated distribution with fixed effects; HC_GMM = simulation with GMM; HC_IV = simulation with IV method; $\mathrm{HC} \_\mathrm{RE}=$ simulation with random effects.

Note that the decrease in the significance level of $\gamma_{d}$ in columns (3)-(4) is due to a blow-up of the standard error of the parameter rather than a decrease in the value of the coefficient. This is a well-known effect due to the use of two-stage procedures like the instrumental variable method used in this regression. Unsurprisingly, the coefficient of migration rate for rich countries $\left(\gamma_{r}\right)$ is never significant at usual confidence levels. These results are consistent with the incentive hypothesis of skilled migration for developing countries explained in a couple of theoretical and empirical papers (Beine et al., 2001 and 2007, Stark et al., 1997, 1998, Stark and Wang, 2002). 
Analysis by country group. Our theoretical model clearly shows that the size of the incentive effect depends on the level of development. Although the crosssection results in Beine et al (2007) do not provide any evidence of a different impact for the poorest countries, it is worth allowing for such differentials in a panel setting. In order to allow for different incentive impacts across types of countries, we make explicit distinction between rich, intermediate and poor countries. In this respect, we use some combination of the classifications provided by the World Bank. In the benchmark classification used in the general model (called classification 1), we include in the rich group nations defined as high-income countries by the World Bank. The remaining countries are included in the group of developing countries. The other classifications are generated by combining the 4 initial groups defined by the World Bank into sub-groups, i.e. high-income, upper-middle-income, lower-middle-income and low-income countries. Distinguishing groups instead of interacting the emigration rate with the GDP per capita level avoids strong problems of endogeneity but also implausible assumptions on the conditional effect of migration. Table 2 provides the definition of the classifications. 
Table 2: Definition of country groups

\begin{tabular}{|c|c|c|c|c|c|}
\hline Classification & Our groups & High-income & $\begin{array}{r}\text { World } \\
\text { Upper-mid }\end{array}$ & $\begin{array}{l}\text { Bank } \\
\text { Lower-mid }\end{array}$ & Low-income \\
\hline \multirow[t]{2}{*}{1} & Rich & & & & \\
\hline & Poor & & $*$ & $*$ & $*$ \\
\hline \multirow[t]{3}{*}{2} & Rich & $*$ & & & \\
\hline & Intermediate & & $*$ & & \\
\hline & Poor & & & $*$ & $*$ \\
\hline \multirow[t]{3}{*}{3} & Rich & $*$ & & & \\
\hline & Intermediate & & $*$ & $*$ & \\
\hline & Poor & & & & $*$ \\
\hline \multirow[t]{3}{*}{4} & Rich & $*$ & $*$ & & \\
\hline & Intermediate & & & $*$ & \\
\hline & Poor & & & & $*$ \\
\hline \multirow[t]{3}{*}{5} & Rich & $*$ & & & \\
\hline & Intermediate+ & & $*$ & & \\
\hline & $\begin{array}{l}\text { Intermediate- } \\
\text { Poor }\end{array}$ & & & $*$ & $*$ \\
\hline
\end{tabular}

The results provided in Table 3 highly depend on the chosen classification of sending countries. Therefore, it is desirable to check the robustness of the results to alternative classification schemes. A further breakdown of the group of the less developed countries might also be interesting. Such a breakdown could show which type(s) of countries tend to drive the positive impact of migration of skilled workers in terms of education. To this aim, we run the same regression procedure as the one conducted in Table 1 but with alternative classifications. We use IV estimation in order to rule out any bias due to reverse causality. All first-stage regression results (not reported here to save space) show that the lagged values of skilled migration rates are strong instruments of the current rates. Column (1) of Table 3 reports the initial results with the benchmark classification. Columns (2) to (5) report the results obtained with classifications 2, 3, 4 and 5 as defined in Table 2 . 
Table 3: Differenciating the effects by country group

$\begin{array}{cccccc}\text { Variables } & (1) & (2) & (3) & (4) & (5) \\ \text { Constant } & -.062^{* * *} & -.066^{* * *} & -.064^{* * *} & -.064^{* * *} & 0.064^{* * *} \\ & (0.018) & (0.018) & (0.018) & (0.019) & (0.019) \\ \beta & -.117^{* * *} & -.122^{* * *} & -.118^{* * *} & -.118^{* * *} & -.118^{* * *} \\ & (0.008) & (0.009) & (0.008) & (0.008) & (0.010) \\ \gamma_{r} & 0.172 & 0.159 & 0.147 & -.011 & -.146 \\ & (0.321) & (0.320) & (0.328) & (0.190) & (0.329) \\ \gamma_{d} & 0.148^{* *} & - & - & - & - \\ & (0.079) & & & & \\ \gamma_{i} & - & -.066 & -.054 & -.049 & \\ & & (0.217) & (0.129) & (0.150) & \\ \gamma_{i+} & - & - & - & - & -.062 \\ & & & & & (0.223) \\ \gamma_{i-} & - & - & - & - & -.050 \\ & & & & & (0.150) \\ \gamma_{p} & - & 0.187^{* *} & 0.304^{* * *} & 0.305^{* * *} & 0.304^{* * *} \\ \text { Nb. obs. } & 588 & 588 & 588 & 588 & 588 \\ \text { Nb. countries } & 147 & 147 & 147 & 147 & 147 \\ \mathrm{R}^{2} & 0.5552 & 0.5592 & 0.5388 & 0.5382 & 0.5390\end{array}$

Note: Estimated equation (11) in which developing countries are split according to Table 2. Fixed effects $\alpha_{i}$ and $\delta_{t}$ not reported. P-value: ${ }^{*} \mathrm{p}<0.1,{ }^{* *} \mathrm{p}<0.05,{ }^{* * *} \mathrm{p}<0.01$. All regressions are estimated with instrumental variables. Lagged values of emigration rates are used as instruments of current values

Results reported in Table 3 provide a strikingly similar picture as the one given before. The results support the catching-up hypothesis and deliver similar speeds of convergence. Concerning the influence of migration rates on long-run levels of human capital, the results allow to refine the previous interpretation. It is seen that the positive incentive impact of migration rates of skilled workers is driven by the effects peculiar to the poorest countries. Results obtained with classifications (3) to (5) in which low-income countries (defined as in the World Bank claissification) are isolated, show that migration rates of poor countries exert strong, robust and positive effects in terms of human capital accumulation. In column (2), this result still holds 
when lower-middle-income countries are associated to low-income countries, but the coefficient is much lower and less significant. Once again, this is consistent with the idea that the incentive effect concerns mainly the poorest countries.

We conclude that a strong incentive effect is at work in low-income countries. By increasing the expected return to education, migration prospects foster the number of natives investing in human capital. In poor countries, such an incentive effect makes the global impact of the brain drain on human capital ambiguous. In the middleincome and rich countries, we find no evidence of a positive incentive effect. The brain drain then unambiguously reduces the stock of human capital in these countries.

\section{$5 \quad$ Who are the potential winners?}

Our empirical analysis reveals that skilled migration prospects foster human capital formation of natives originating from low-income countries. As some of them will leave (or never return after being trained abroad), the net effect on the quantity of human capital remaining in the country is ambiguous. A brain gain can be obtained if skilled emigration rates are not too high. To evaluate the global impact of migration prospects on human capital, let us use equation (11) and compute the steady state proportion of native educated as a function of fixed effects and the skilled emigration rate. We have

$$
h_{i, s s}=\exp \left[\frac{\alpha+\alpha_{i}+\delta_{s s}+\gamma_{p} m_{i, s s}^{p}}{-\beta}\right]
$$

where $\delta_{s s}, m_{i, s s}^{p}$ are the fixed effects and skilled emigration rates observed in 2000 (superscript $p$ stands for low-income countries).

Then, we compute the effect on residents' human capital $\left(H_{i, s s}\right)$ by dropping 
emigrants from the native population:

$$
H_{i, s s}=\frac{\left(1-m_{i, s s}\right) h_{i, s s}}{1-m_{i, s s} h_{i, s s}-\underline{m}_{i, s s}\left(1-h_{i, s s}\right)}
$$

where $\underline{m}_{i, s s}$ is the rate of migration of the unskilled.

Given the parameter set $\left(\alpha, \alpha_{i}, \gamma_{p}\right)$, Figure 3 presents the simulated impact of skilled emigration rates and country-specific fixed effects on the long-run proportion of educated in poor countries. The simulation is based on the following assumptions: $\underline{m}_{i, s s}=m_{i, s s} / 10$ (in poor countries, skilled migration rates are on average ten times as high as unskilled migration rates) and $\delta_{s s}=\delta_{2000}$. We let the country-specific fixed effect vary between -.6 and -.3, which is the range of values obtained in poor countries.

It clearly appears that the fixed effect has a strong impact on the long-run level of human capital, especially for low skilled emigration rates. This result is not surprising as fixed effects captures many determinants of human capital formation such as education policies, returns to skills, governance, ethnic discrimnation, etc. The skilled emigration induces an inverted U-shaped effect on the long-run stock of human capital. The latter result is highly compatible with the theoretical model depicted above. We observe that moderate skilled emigration rates have a small but positive impact on human capital. However, when the emigration rate exceeds 50 percent, the human capital loss increases exponentially compared to the closed economy benchmark. The "optimal" migration rate (i.e. maximizing residents' human capital) is around 20 percent in countries where the fixed effect is very low and around 30 percent in countries where the fixed effect is not too low. The brain drain is lower than 20-30 percent in many low-income countries, except in the smallest states. Our results suggest that most low-income countries could experience a net brain gain. 
Figure 3: Skilled emigration rates, fixed effects and residents' human capital in low-income countries

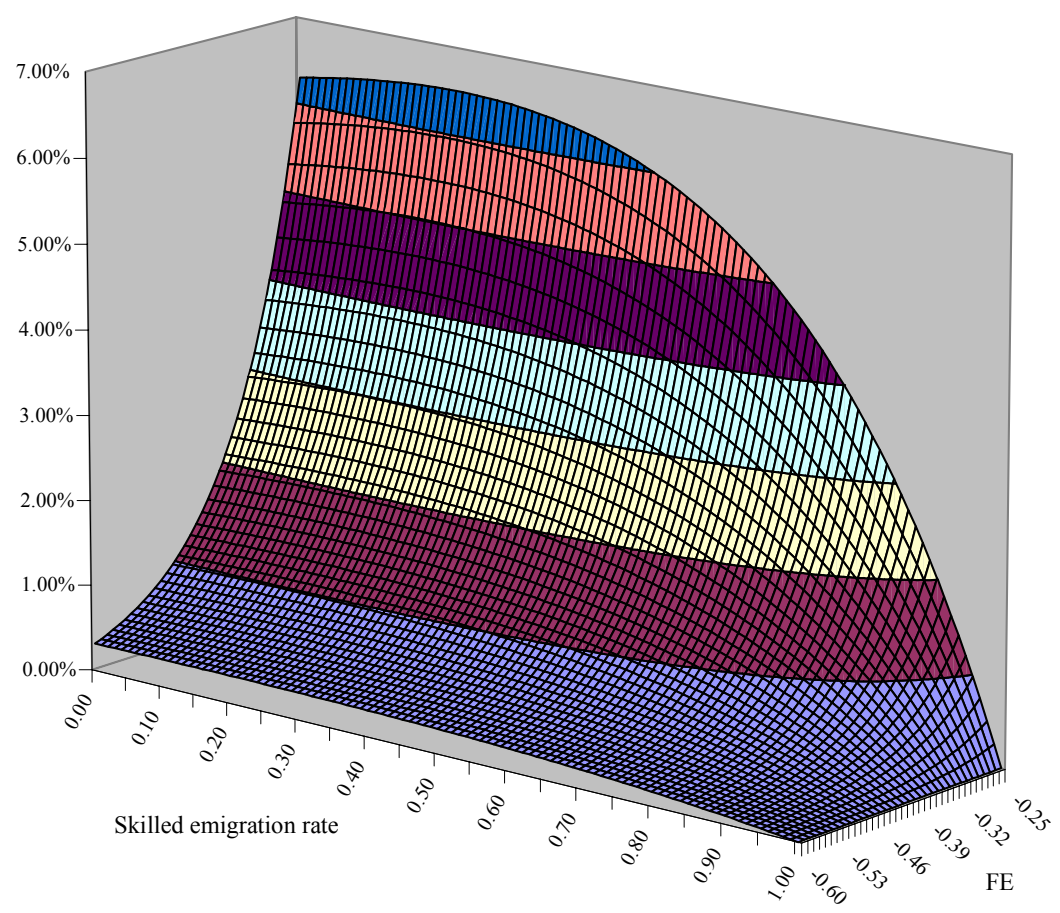

In poor countries, fixed effects range from -0.6 to -0.3 . Simulation are based on classification 3 in Table 2, and column (3) in Table 3.

\section{Conclusion}

The new growth literature has stressed the role of human capital for economic development. Hence, the emigration of skilled workers is usually blamed for depriving developing countries of their most talented workers. This view has been challenged by a new literature putting forward multiple positive feedback effects for sending countries. However, the empirical literature on the consequences of the brain drain remains quite poor. In particular, several contributions demonstrate that skilled migration prospects can increase human capital accumulation ex-ante, possibly turn- 
ing the brain drain into a brain gain. Due to data limitations, existing empirical studies are based on cross-sectional regressions and suffer from the bias of omitted variables/unobserved heterogeneity, and the difficulty to solve potential endogeneity problems.

Taking advantage of a new panel data set of emigration rates by education level, this paper confirms the existence of a strong incentive mechanism when unobserved heterogeneity and endogeneity issues are serioulsy addressed. In addition, it comes out that such an incentive effect is only perceptible among low-income countries for which migration premia are high. In middle-income and rich countries, migration prospects have no significant impact on education decisions so that skilled emigration rates directly reflect their loss of human capital. In poor countries, the net effect of the brain drain on human capital is positive when the brain drain is not too high (say lower than 30 percent). This is the case of many countries, except the smallest states. When the emigration rate exceeds that threshold, the cost of the brain drain increases exponentially.

Many questions and sources of uncertainty remain in the literature on the consequences of the brain drain. Where did migrants acquire education? Can the outsourcing of education explain the positive correlation between emigration rates and human capital investments? Does the outsourcing of education lead to important return flows of educated migrants? Is the incentive effect depending on the destination? Does the brain drain induce severe occupational shortage? In our regressions, many of these factors (outsourcing of education, return migration, etc) are likely to be assimilated to pure incentive mechanisms. It would be helpful to build new micro surveys explicitly conducted to capture the relationship between emigrants and their country of origin, to collect more data and case-studies on the sectoral impact of the brain drain, to 
improve the quality of human capital indicators of residents. However, within the limits of a macroeconomic approach, our analysis provides an additional argument in favor of the incentive mechanism. A global research agenda based on multi-level studies (combining country cases, micro and macro studies) would be needed to refine the nature of the effect captured in our regressions.

\section{References}

Arellano, M. and S. Bond (1991) : "Some tests of specification for panel data: Monte Carlo evidence and an application to employment equations", The Review of Economic Studies 58: 277-97.

Arellano, M. and O. Bover (1995): "Another look at the instrumental variable estimation of error-components models", Journal of Econometrics 68: 29-51.

Azariadis, C. and A. Drazen (1990): "Threshold externalities in economic development", Quarterly Journal of Economics, 105, 2: 501-26.

Azariadis, C. and J. Stachurski (2005): Poverty traps, in Aghion, P. and S. Durlauf, Handbook of Economic Growth, forthcoming at Elsevier, North-Holland.

Barro, R.J. and J.W. Lee (2001): "International Data on Educational Attainment: Updates and Implications", Oxford Economic Papers, 53(3), 541-563.

Beine, M., F. Docquier and H. Rapoport (2001): "Brain Drain and Economic Growth: Theory and Evidence", Journal of Development Economics, 64, 1: 275-89.

Beine, M., F. Docquier and H. Rapoport (2007): "Brain Drain and human capital formation in developing countries: Winners and Losers", Economic Journal, forthcoming.

Blundell, R. and S. Bond (1998): "Initial conditions and moment restrictions 
in dynamic panel data models", Journal of Econometrics 87: 115-43.

Carrington, W.J. and E. Detragiache (1998): How Big is the Brain Drain?, IMF Working Paper, 98.

Cohen, D. and M. Soto (2001): "Human capital and growth: good data, good results", CEPR Discussion Paper, 3025.

Commander, S., R. Chanda, M. Kangasniemi and L.A. Winters (2004): Must skilled migration be a brain drain? Evidence from the Indian software industry, Discussion paper n. 1422, IZA-Bonn.

de la Fuente, A. and R. Domenech (2002): "Human capital in growth regressions: how much difference does data quality make? An update and further results", CEPR Discussion paper, 3587.

Defoort, C. (2006): Long Trends in International Skilled Migrations: Evidence from the 6 Major Receiving Countries, Mimeo, University of Louvain.

Docquier, F., O. Lohest and A. Marfouk (2006): "Brain drain in developing countries", World Bank Economic Review, forthcoming.

Docquier, F. and A. Marfouk (2006): "International migration by educational attainment, 1990-2000 (Release 1.1)", in: Caglar Ozden and Maurice Schiff (eds). International Migration, Remittances and Development, McMillan and Palgrave: N.Y.

Domingues Dos Santos, M. and F. Postel-Vinay (2003): "Migration as a source of growth: the perspective of a developing country", Journal of Population Economics 16(1), 161-75.

Domingues Dos Santos, M. and F. Postel-Vinay (2004): "The impact of temporary migration on human capital accumulation and economic development, Brussels Economic Review, 47(1), Special issue on skilled migration.

Easterly, W. (2002): The Elusive quest for growth, The MIT Press, Cambridge, 
MA.

Faini, R. (2003): Is the brain drain an unmitigated blessing?, UNU-WIDER Discussion Paper No 2003/64, September.

Gould, D. (1994): "Immigrants Links to the Home Countries: Empirical Implication for U.S. bilateral Trade Flows", Review of Economics and Statistics 76(2), $302-316$.

Kangasniemi, M., L.A. Winters and S. Commander (2004): Is the medical brain drain beneficial? Evidence from overseas doctors in the UK, Mimeo, CNEM, London Business School.

Islam, N. (1995): Growth Empirics: a Panel Data Approach, Quarterly Journal of Economics, 110, 4, 1127-1170.

Kugler, M. and H. Rapoport (2006): "Migration and FDI: complements or substitutes?", paper presented at the CEPR/ESF conference on "Outsourcing, Migration, and the European Economy", Rome.

Lucas, R.E.B. (2004): International migration regimes and economic development, Report for the Expert Group on Development Issues (EGDI), Swedish Ministry of Foreign Affairs.

Mankiw, N.G.., D. Romer. and D. Weil (1989): A Contribution to the Empirics of Economic Growth, Quarterly Journal of Economics, 107, 407-437.

Mariani, F. (2005): On some consequences of international migration for economic growth and politics, Doctoral dissertation, Catholic University of Louvain.

Mountford, A. (1997): Can a brain drain be good for growth in the source economy?, Journal of Development Economics, 53, 2: 287-303.

Nickell, S. (1981): "Biases in Dynamic Models with Fixed Effects", Econometrica, 49(6), 1417 - 1426 . 
Rauch, J. E. and V. Trindade (2002): "Ethnic Chinese networks in international trade", Review of Economics and Statistics, 84, 1: 116-30.

Rauch, J. E. and A. Casella (2003): "Overcoming informational barriers to international resource allocation: Prices and Ties", Economic Journal, 113, 484: 2142.

Rosenzweig, M. (2007): Higher Education and International Migration in Asia: Brain Circulation, paper presented at the RBCDE conference, Beijing, January.

Stark, O., C. Helmenstein and A. Prskawetz (1997): A brain gain with a brain drain, Economics Letters, 55: 227-34.

Stark, O., C. Helmenstein and A. Prskawetz (1998): Human capital depletion, human capital formation, and migration: a blessing or a 'curse'?, Economics Letters, 60, 3: 363-7.

Stark, O. and Y.Q. Wang (2002), Inducing human capital formation: migration as a substitute for subsidies, Journal Public Economics, 86(1): 29-46.

Vidal, J.-P. (1998): The effect of emigration on human capital formation, Journal of Population Economics, 11, 4: 589-600.

World Bank (2006): Global Economic Prospects, World Bank, Washington DC. 
Département des Sciences Économiques de l'Université catholique de Louvain

Institut de Recherches Économiques et Sociales

Place Montesquieu, 3

1348 Louvain-la-Neuve, Belgique 